Francisco Castañeda

\title{
Presentación de don Juan Perelló como miembro académico ${ }^{(*)}$
}

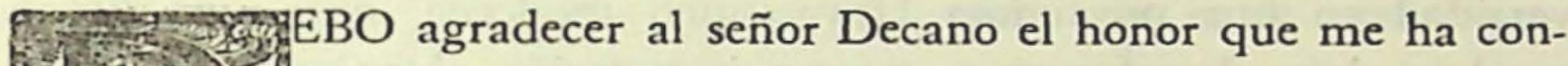
$650 \%$ (3) 3 ferido al comisionarme para recibir en el seno de nuestra 5. H. . 5acultad, en el carácter de Miembro Académico, al dis-

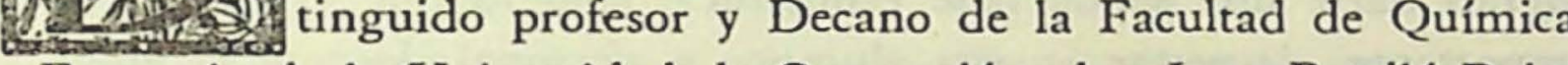
y Farmacia de la Universidad de Concepción, don Juan Perelló Puig. La Facultad de Química y Farmacia de la Universidad de Chile ha sido siempre muy parca al conferir título de Miembro Académico, porque ha estimado que no sólo deben considerarse para este objeto los merecimientos de carácter didáctico y científico, sino que el espíritu de abnegación y de sacrificio por los altos ideales que llevan hacia el progreso de las ciencias y profesiones que se enseñan en nuestras escuelas. De todas estas condiciones ha dado sobradas muestras en su ascendente carrera profesional y científica, el profesor Perelló, como lo veremos en el siguiente bosquejo biográfico.

(*) Texto del discurso de presentación pronunciado por el profesor de Química Orgánica de la H. Facultad de Química y Farmacia de la Universidad de Chile en el acto de recepción del profesor señor Juan Pcrelló P., como Miembro Académico de la Facultad ya indicada, el 17 de agosto de 1956. El señor Perelló desempeña actualmente el cargo de Director de la Escuela de Química y Farmacia de la Universidad de Concepción y es además profesor de Química Orgánica. Es también Director del Instituto de Química Orgánica y desempeñó el decanato de su Facultad durante varios períodos.
\end{abstract}


El profesor Perelló nace en Barcelona a comienzos del presente siglo, pertenece, por consiguiente, a la intrépida raza española a la cual no le impidió un océano desconocido el conquistar un mundo nuevo. Con el espíritu ancestral de su raza llega a nuestro país a la temprana edad de tres años y se radica con su familia en las ciudades de Concepción y Los Angeles, en donde efectúa sus estudios primarios, secundarios y universitarios, tocándole en suerte ser uno de los primeros egresados de la naciente Universidad de Concepción en la cual, con tanto tino y eficiencia iba, años más tarde, a dirigir la Facultad de Química y Farmacia.

Es en este ambiente y en compañía de un grupo de profesionales donde inicia sus labores docentes y se dedica a la gigantesca tarea de consolidar y transformar su rudimentaria y naciente Universidad en una prestigiosa Universidad moderna, obra que llevan a cabo a base de esfuerzo y constancia y cariño obteniendo como resultado la floreciente Universidad de Concepción, a la cual no sólo logran darle una sólida base económica, sino lo que es mucho más importante, despertar en sus alumnos y personal docente el amor a las ciencias y al estudio y un espíritu de superación constante, lo que conjuntamente con el deseo de servir y ser útil a la humanidad, constituyen el alma de una Universidad.

El profesor Perelló escala paso a paso, pero con seguridad y precisión, toda la escala de la carrera docente, desde el puesto de ayudante de las cátedras de Química Analítica y Orgánica en 1923 a profesor de Química Física en la Facultad de Odontología en 1928. Profesor de Química Orgánica en la Facultad de Química y Farmacia en 1942 hasta llegar, en 1946, a Director y Decano de la Facultad de Química y Farmacia, y es desde estos cargos donde desarrolla un admirable espíritu de organización. Sacrificando su tiempo, sus energías y hasta sus más íntimas ansias de investigador, logra colocar a la Escuela de Química y Farmacia de la Universidad de Concepción entre las más avanzadas de nuestra América. Es uno de los primeros dirigentes universitarios que comprenden que el 
desarrollo de la investigación científica requiere en forma indispensable, no sólo la imprescindible preparación intelectual, sino también los medios materiales para llevarla a cabo, el tiempo suficiente para desarrollarla y la necesaria tranquilidad de quienes la emprenden, para que dedicándose a ella en forma absoluta, pueda fructificar provechosamente en beneficio de la humanidad. De acuerdo con estos principios trata por todos los medios a su alcance de vincular lo más estrechamente posible a todos los miembros de su Facultad en jornadas completas de trabajo de modo que puedan vivir por su Universidad y para su Universidad.

A pesar de esta intensa labor, el espíritu inquieto del profesor Perelló se desborda hacia el campo profesional a donde lo llevan el cariño a su profesión y el afecto hacia sus colegas; y es así como no ha habido Congreso ni Convención profesional que no lo cuente entre sus más destacados miembros, y aún más, atravesando nuestras fronteras va a desempeñar un lucido papel en congresos científicos y profesionales del extranjero.

Su labor científica y docente es tan intensa y provechosa como la administrativa y de organización, orienta y desarrolla la labor de investigación científica de su cátedra que fructifica en más de cien interesantes tesis de grado, muchas de las cuales he tenido el placer de conocer personalmente y de comprobar su alto interés científico. Dicta cursos relacionados con su especialidad en las principales ciudades del país y colabora con trabajos científicos en numerosos congresos de química.

Toda esta interesante y nutrida labor científica no podía permanecer anónima y es así como numerosas instituciones extranjeras, profesionales, docentes y científicas, se honran llamándolo a su seno, entre ellas podemos indicar la Sociedad Peruana de Química, la Sociedad Farmacéutica de Cuba, la Facultad de Farmacia y Bioquímica de la Universidad Mayor de San Marcos de Lima, etc.

A todas estas excelsas cualidades que adornan la personalidad del profesor Perelló, debemos agregar las condiciones de caballerosidad e hidalguía que hacen que las personas que han tenido el pri- 
vilegio de compartir su amistad, o su pan en la mesa de su distinguido hogar, conserven el recuerdo de esos momentos como los más dilectos de su vida.

Señores, espero que a través de este esbozo biográfico hayáis podido apreciar debidamente la recia personalidad del profesor Perelló a quien la Facultad de Química y Farmacia de la Universidad de Chile se honra con recibir en estos momentos como su Miembro Académico. 